\title{
THE EFFECTS OF PERSONAL TRAITS AND GAME FACTORS ON IMMORAL GAME BEHAVIOR: FOCUSED ON <LEAGUE OF LEGENDS>
}

\author{
Sungje Lee, Jeonyoung Kong, Meiying Piao and Euijun Jeong \\ Dept. of Culture Contents, \\ Konkuk University, 120 Neung Dong-Ro, \\ Gwang Jin-Gu, Seoul \\ South Korea
}

\begin{abstract}
As digital games have become popular, the number of incidents and the degree of damage caused by immoral game behavior (such as "flaming", "trolling") are on the rise. But few studies have been conducted to explore the antecedents to such flaming and trolling. Therefore, this study empirically examined the effects of aggression and self-esteem, and game factors (game moral positioning, game motivations, gaming time) on immoral game behaviors with participating game players of <League of Legends>. Results showed that game moral positioning (i.e., a tendency to choose evil characters or activities) and advancement motivation (i.e., focus on competition and growth) positively affect immoral game behaviors. While "fun/interest" motivation has a negative effect on immoral game behaviors. In addition, gaming time did not affect flaming and trolling. These results show that preference of an evil moral identity or competitive motivation in a game could affect immoral game behaviors. These results show that moral preference of an evil identity or competitive motivation in a game could affect immoral game behaviors. And it could impede delectable game experience. Furthermore, meanwhile, aggression increase immoral game behaviors. But self-esteem did not affect immoral game behaviors. Finally, moral positioning moderates the impact of aggression and advancement motivation on immoral game behaviors. Consequently, digital games that solicit moral deviations should seek ways to offer unique entertainment, and to encourage game users not to put an obstacle to the other game users' positive gaming experience due to their excessive immersion in evil characters or identities. As suggested, game producers must offer diverse types of gaming systems or to organize special game modes than those promoting excessive competitiveness for the pleasure and enjoyment of various types of users.
\end{abstract}

\section{KEYWORDS}

Immoral Game Behavior, Game Moral Positioning, Game Motivation, Aggression, Self-Esteem

\section{INTRODUCTION}

As digital games have become popular, the number of incidents and the degree of damage caused by immoral game behavior are on the rise. Such behaviors obstruct others' comfortable gaming experience and the spirit of fair competition (Fragoso, 2016), thus requiring an urgent study on the prevention and eradication of immoral game behavior. In particular, flaming and trolling have led to difficult situations as these occur more often than match-fixing or the use of illegal programs, resulting in considerable displeasure.

To address these issues, game developers are restricting abusive language and trolling in games by using various internal and external measures. For example, Riot Games, the developer of the globally sensational game, <League of Legends>, has developed its own slang detection system and is running a jury system in the game to deter abusive language in the South Korean server (League of Legends, 2016; Kou \& Nardi, 2013). Despite such efforts, however, flaming and trolling in digital games still pose grave concerns (Seo, 2015).

Flaming is an actual phenomenon that frequently occurs in the environment of computer-mediated communication (CMC) (Hwang et al, 2016; Lea et al, 1992). It is categorized as a negative behavior that expresses hostility toward others or subjects indifferent to oneself by using vicious language (Moor, 2010). 
Previous studies have reported that flaming stems from self-esteem (Suh, 2012; Brewer \& Kerslake, 2015), game motives (Alonzo \& Aiken, 2004; Chu et al, 2013; Bishop, 2014), and social identification (Lee, 2005).

Trolling is a type of behavior that intentionally dismisses cooperating with a user or carries out certain actions repetitively to provide advantages to the user's competitors. Recently, trolling has often been used as an online language with the aim of intentionally making others angry (Thacker \& Griffiths, 2012). According to previous studies, trolling is affected by personal factors like aggression (Buckels et al, 2014; Lee et al, 2016; Patchin \& Hinduja, 2010), game motives like enjoyment (Graham \& Gosling, 2013) and the structural characteristics of digital games where loose regulations are applied (Seo, 2015).

As one of the antecedents to game behaviors, game motivation is believed to play an important role in the use of flaming and trolling behaviors. The use and gratification theory says that game users are clearly aware of their motives, which they must satisfy and for which they actively use media. Thus, specific motives for the use of media affect the users' media use or behavioral patterns, including gaming behaviors (Stafford et al, 2004; Zhang et al, 2011; Yee, 2006a; Yee, 2006b; Kim \& Park, 2007). Billieux et al. (2013), for example, conducted research that focused on "World of Warcraft," and showed that motivations, such as advancement and escapism, affected immoral behaviors, like illegal player killing (PK).

As personal traits, self-esteem and aggression have also been reported to affect immoral (Brown et al, 2011; Donnellan, 2005; Kaplan, 1982; Berkowitz, 1993). Self-esteem is the degree of awareness of one's affection for oneself or the degree of one's positive evaluation of oneself (Larson, 1992) Donnellan et al. (2005) reported in their longitudinal study that low self-esteem is related to anti-social behavior. In line with this study, similar research also pointed out that low self-esteem is a key factor in cyber bullying and misdeed (Kaplan, 1982). Aggression refers to all forms of behavior that aim to damage others physically or psychologically (Berkowitz, 1993), which has been used as a parameter for predicting anti-social behavior or of deviant behaviors like misdeeds or crimes (Jung, 2011; Olweus, 1979; Thomas, 2006). Regarding immoral behaviors in video games, Lee et al. reported that high levels of aggression lead to trolling behaviors (Lee et al, 2016).

Furthermore, moral positioning by players during gaming (i.e., game moral positioning) may play a key role in explaining in-game immoral behaviors. Moral positioning means an individual under social conflict is using moral context and moral tendencies to understand the moral identity and meaning of the subject and object (Sammut \& Gaskell, 2010). Individuals, when facing conflicts, refer to other viewpoints or to the roles of the other members, and, through this process, they verify their position or pursue a specific behavioral objective (Triberti et al, 2015). In this context, it is believed that moral positioning is a process in which one judges his or her position or behavior by referring to moral identity, even in the online space. Triberti et al., for example, argued that moral positioning may affect the occurrence of aggressive behavior in online games.

However, there have been few studies that attempted to use the players' game motivations and moral positioning with regards to immoral behaviors in multi-user online games. Therefore, this study empirically examined the effects of moral positioning, game motivations, and personal traits (i.e., aggression and self-esteem) on immoral behaviors with the controls of the users' gaming habits and demographic variables.

\section{METHOD}

$<$ League of Legends (LOL)>, a PC-based, multi-user online game, has been distributed globally and is a top game in South Korea. A survey was conducted with the participants recruited from "League of Legends Inven" (lol.inven.co.kr) and "League of Legends Hungryapp" (leagueoflegends.hungryapp.co.kr), the top two LOL communities in Korea.

A total of 401 study participants joined. The data from 343 participants, excluding those with missing values, were selected for analysis. They included 299 males $(87.1 \%)$, whose average age was around 26 years old. The average daily gaming hours was $1.54 \mathrm{hrs}$. ( $\mathrm{SD}=54 \mathrm{~min}$.).

Based on previous studies (Lee, 2003) six questions were adapted to measure FT (flaming and trolling) behaviors. Flaming items $(\alpha=.862)$ included curses and mockery (e.g., "I curse when I don't like the playing style of the other game users," "I mock or ridicule the other game users to make them feel bad"). Trolling items $(\alpha=.859)$ covered intentional negligence or behavior that intentionally put one's ally in danger (e.g., "I do not participate in the game or let my competitor kill my character when I don't like the playing style of the other game users"). 
In terms of game motivations, 17 items from the game use motive scale (Motivations for Playing Online Games) were used (Park \& Song, 2010). The sub-scale items were social relationship $(\alpha=.872)$, acquisition (of unique personality) ( $\alpha=.775)$, escapism ( $\alpha=.738)$, advancement (of competitive game skills) $(\alpha=.805)$, and fun/interest $(\alpha=.847)$.

To measure self-esteem and aggression, Rosenberg's Self-Esteem Scale (Rosenberg, 1965) $(\alpha=.862,10$ items) and The Short-Form Buss-Perry Aggression Questionnaire $(\alpha=.882,12$ items) were used, respectively (Diamond et al, 2005). Finally, in terms of game moral positioning, modified scales by Triberti et al. were used (Triberti et al, 2015). The 5 items included preference for evil roles and characters (e.g., "I tend to choose evil game roles," "I prefer to make evil choices.", $\alpha=.908$ ).

\section{RESULT}

The variables that had significant positive relations with flaming and trolling were aggression ( $\mathrm{r}=.509$; $\mathrm{p}<.001)$, game moral positioning $(\mathrm{r}=.466, \mathrm{p}<.001)$, and motivations such as social relationship $(\mathrm{r}=.133$, $\mathrm{p}<.05)$, escapism $(\mathrm{r}=.314, \mathrm{p}<.001)$, advancement $(\mathrm{r}=.297, \mathrm{p}<.001)$. Fun/interest $(\mathrm{r}=-.203, \mathrm{p}<.001)$ showed a negative relationship. In the regression analysis, moral positioning demonstrated positive effects on flaming and trolling (see Model1, Table 1). In the game motivations, advancement of competitive game skills showed a positive effect $(\beta=.199, \mathrm{p}<.001)$ whereas fun/interest had a negative effect on immoral behaviors $(\beta=-.214$, $\mathrm{p}<.001)$.

In terms of control variables, there were no significant effects on gaming time and age on the behaviors. In terms of personal traits, aggression had a positive effect $(\beta=.384, p<.001)$, while self-esteem had no significant effect.

Game moral positioning showed interactive effects with aggression and advancement motivation (see Figure 1). In the group of higher preference for evil-role characters, a higher level of aggression increased the level of immoral behaviors while there was no significant change for the lower group. Likewise, in the higher group, higher level of advancement augmented the degree of immoral behaviors.

\section{DISCUSSION}

Game moral positioning played a key role in the degree of flaming and trolling. Moral positioning increased the level of immoral behaviors and showed interactive effects with aggression and advancement motivation. Though the levels of aggression and advancement strongly increased the level of flaming and trolling, moral positioning moderated the effects. These results proved that preference of an evil moral identity in a game could affect one's in-game immoral behaviors, such as verbal hostility and anti-user behaviors, which could impede fair competition and gaming pleasure. They also implied that the moral preferences of the narrative or playing style in the system might cause malicious and rude tendencies (Happ et al. 2013; Hollingdale \& Greitemeyer, 2013).

In terms of game motivations, the advancement of competitive game skills had a positive effect on immoral behaviors. In line with the competitive playing environments of <League of Legends>, the obsessive pursuit of winning might cause aggressive language and behaviors. For example, obsessive competition might lead one to coerce his or her team members more than it would be necessary, or to slight others who have fallen behind. Thus, it is expected that the experience of failure in a competition could cause immoral game behaviors under the guise of "enjoyment," in which users hide their disappointment and misery.

Fun/interest, however, was shown to have a negative effect on flaming and trolling. This means that game users who are more interested in leisurely pursuits tend to manifest less immoral behaviors in a game. Furthermore, it implies that, from the perspective of game content design, a comfortable game environment can be established by offering diverse types of entertaining contents than stressing excessive competitiveness. 
Aggression had a positive effect on flaming and trolling. This result showed that, in the real world, game users' aggression might lead to immoral behavior in online games, and offered interesting research implications on the relation between digital gaming and aggression. On the other hand, self-esteem had no significant effect. This result implied that positive self-evaluation affected digital game behavior, which might be closer to online efficacy than to organic self-esteem. Because online/offline self-efficacy affects each other (Jeong \& Kim, 2011), even with higher levels of organic self-esteem, if one has lower online (or game) self-efficacy, one may become more easily agitated or frustrated under stimulating circumstances within a game.

Table 1. Regression Analysis

\begin{tabular}{|c|c|c|c|c|}
\hline \multirow[b]{2}{*}{ Variables } & \multicolumn{2}{|l|}{ Model 1} & \multicolumn{2}{|l|}{ Model 2} \\
\hline & $\beta$ & SEB & $\beta$ & SEB \\
\hline \multicolumn{5}{|l|}{ Controls } \\
\hline Gender & $-.085 *$ & .093 & $-.100 *$ & .089 \\
\hline Age & -.075 & .006 & -.063 & .006 \\
\hline $\begin{array}{l}\text { Gaming Time } \\
\text { (Daily gaming hours) }\end{array}$ & .022 & .026 & -.004 & .025 \\
\hline \multicolumn{5}{|l|}{ Moral Positioning } \\
\hline $\begin{array}{l}\text { Game Moral Positioning } \\
\text { (GMP) }\end{array}$ & $.243 * * *$ & .033 & - & - \\
\hline \multicolumn{5}{|l|}{ Personal Traits } \\
\hline Aggression (AG) & $.384 * * *$ & .050 & $.691 * * *$ & .095 \\
\hline Self-esteem (SE) & .002 & .049 & -.017 & .048 \\
\hline AG x GMP & & & $.352 * *$ & .035 \\
\hline SE x GMP & & & .049 & .008 \\
\hline \multicolumn{5}{|l|}{ Motivation } \\
\hline Relationship & .058 & .037 & .054 & .036 \\
\hline Acquisition & -.053 & .041 & .014 & .040 \\
\hline Escapism & .028 & .047 & .019 & .045 \\
\hline Advancement (AD) & $.199^{* * *}$ & .036 & $.404 * * *$ & .066 \\
\hline Fun/interest (FN) & $-.214 * *$ & .038 & $-.228 * * *$ & .052 \\
\hline $\mathrm{AD} \times \mathrm{GMP}$ & & & $.332 * * *$ & .024 \\
\hline FN x GMP & & & -.072 & .016 \\
\hline $\mathrm{R}^{2}$ & \multicolumn{2}{|l|}{.501} & \multicolumn{2}{|l|}{.551} \\
\hline F-value & \multicolumn{2}{|c|}{$27.175 * * *$} & \multicolumn{2}{|c|}{$28.182 * * *$} \\
\hline
\end{tabular}

Note. Dependent variable: Flaming \& Trolling.

Due to high collinearity (VIF= 34.593), GMP was not used in Model2

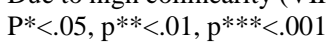



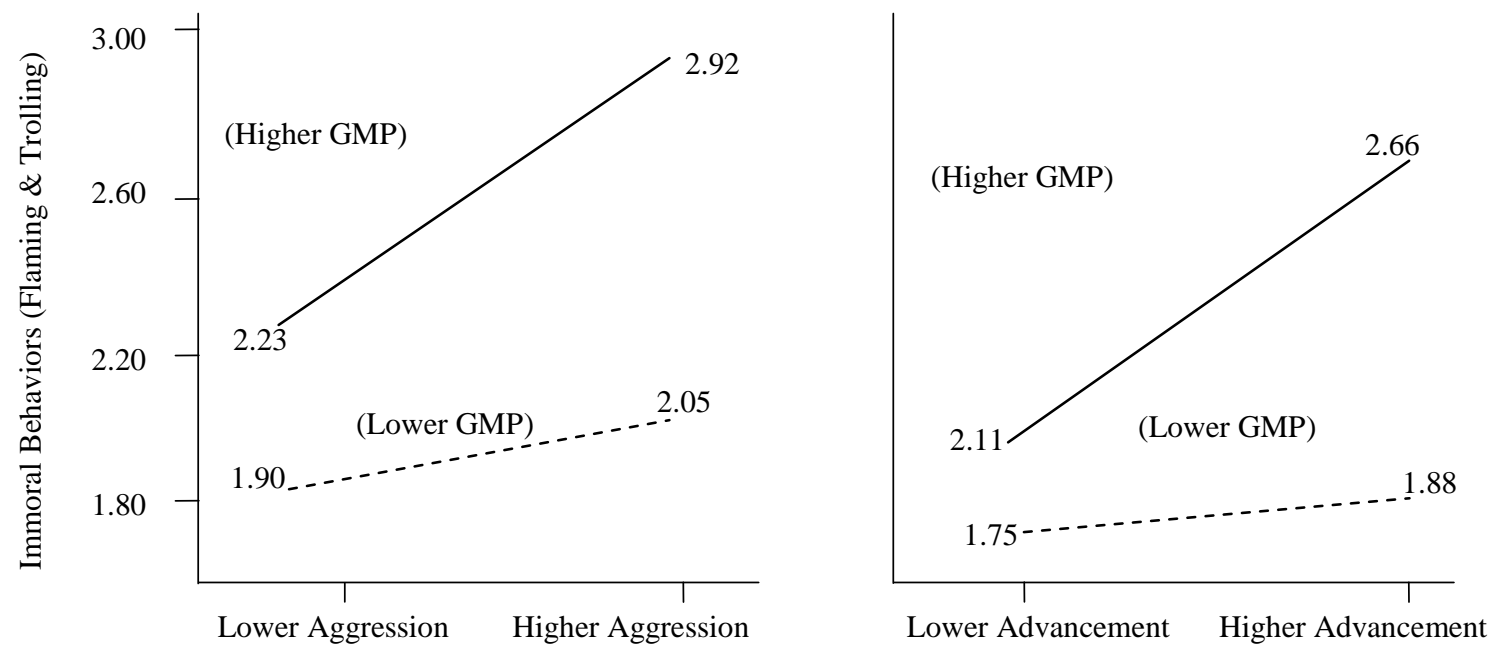

Figure 1. Interaction Effects of Game Moral Positioning with Aggression and Advancement

It is interesting to note that gaming time did not affect flaming and trolling. This result is consistent with that of a trolling study on Korean gamers. The results supported the argument that playing games for a long time does not necessarily increase immoral game behavior. Consequently, in the research on immoral game behavior, it is necessary to consider diverse variables like structural traits of games and individuals' internal factors rather than the hours devoted to gaming.

This study has several limitations. First, this study does not guarantee causal relationships. Further research must be conducted, including a longitudinal study, to determine causality. Next, empirical data were collected from just one country. Future studies may replicate this study from a global perspective to include diverse cultural environments.

In conclusion, this study showed the important roles of moral positioning and game motivations in multi-user online games. Those results imply that, in a multiplayer gaming environment, users are not forced to immerse themselves in immoral behaviors only because these digital games are "virtual." The competitive environment that entices users' motivation to become more competitive can make other players uncomfortable since one, especially for those who are highly aggressive, can assume an evil identity to remain motivated. Consequently, digital games that solicit moral deviations should seek ways to offer unique entertainment, and to encourage game users not to put an obstacle to the other game users' positive gaming experience due to their excessive immersion in evil characters or identities. As suggested, game producers must offer diverse types of gaming systems or to organize special game modes than those promoting excessive competitiveness for the pleasure and enjoyment of various types of users.

\section{REFERENCES}

Alonzo M, Aiken M. Flaming in Electronic Communication. Decision Support Systems 2004; 36:205-213.

Berkowitz L, 1993. Aggerssion: Its causes, conseqiences, and control. philadelphia : Temple University Press.

Billieux et al, 2013. Why do you play World of Warcraft? An in-depth exploration of self-reported motivations to play online and in-game behaviors in the virtual world of Azeroth. Computers in Human Behavior, 29, 103-109.

Bishop J, 2013. The effect of de-individuation of the internet troller on criminal procedure implementation: An interview with a hater, International Journal of Cyber Criminology, 7, 28-48.

Brewer G \& Kerslake J, 2015. Cyberbullying, self-esteem, empathy and loneliness. Computers in Human Behavior, 48, 255-260. 
Brown J et al, 2001. From the top down: Self-esteem and self-evaluation. Cognition and Emotion, 15, 615-631.

Buckels et al, 2014. Trolls just want to have fun. Personality and Individual Differences, 67, 97-102.

Chu K et al, 2013. A Study on Factors Influencing on Flaming Behavior in Cyberspace. Journal of Cultural Industry Studies, 13, 47-57.

Diamond P et al, 2005. Factor structure of the Buss-Perry Aggression Questionnaire (BPAQ) with mentally ill male prisoners. Criminal Justice and Behavior, 32, 546-564.

Donnellan et al. 2005, Low self-esteem is related to aggression, antisocial behavior, and delinquency, Psychological Science, 16, 328-335.

Fragoso S, 2016. HUEHUEHUE I' m BR : spam, trolling and griefing in online games. Revista FAMECOS : mídia, cultura e tecnologia, 22, 147-164.

Graham L \& Gosling S, 2013. Personality profiles associated with different motivations for playing World of Warcraft, Cyberpsychology, Behavior, and Social Networking,16, 189-193.

Happ C et al, 2013. Superman vs. BAD man? The effects of empathy and game character in violent video games. Cyberpsychology, Behavior and Social Networking, 16, 774-778.

Hollingdale J \& Greitemeyer T, 2013. The changing face of aggression: The effect of personalized avatars in a violent video game on levels of aggressive behavior. Journal of Applied Social Psychology, 43, 1862-1868.

Hwang J et al, 2016. Cyber neutralisation and flaming. Behaviour \& Information Technology, 35, 210-224.

Jeong E, Kim D, 2011. Social activities, self-efficacy, game attitudes, and game addiction. Cyberpsychology, Behavior and Social Networking, 14, 213-221.

Jung Y, 2011. Early Adolescents' Changes in Aggression and Delinquency According to Using Computer Games: Latent Growth Curve Modeling, Journal of Cybercommunication Academic Society, 28, 89-125.

Kaplan H. 1982. Self-esteem and deviant behavior. Journal of Youth and Adolescence, 4, 175-188.

Kim Y \& Park S, 2007. A Study on the Online Game Use Influences in Game Flow and Addiction: Focusing on the Uses and Gratifications Approach. Korean Journal of Journalism \& Communication Studies, 51, 355-377.

Larson J, 1992. Anger and aggression management techniques through the think first curriculum. Journal of Off ender Rehabilitation, 18, 101-117.

Lea M. et al, 1992. Flaming in computer-mediated communication: Observations, explanations, implication. In: M. Lea, eds. Contexts of Computer-mediated communication. London: Harvester Wheatsheaf.

League of Legends, 2016, Korean slang sanctions system. League of Legends News. http://www.leagueoflegends.co.kr/?m=news\&cate=notice\&mod=view\&schwrd=\&p=1\&idx=253132\#.WBt7X5v_rIU

Lee C, 2004. A Study for Flaming in Virtual Community, Korea Marketing Review, 18, 3-30.

Lee E, 2004. Effects of Visual Representation on Social Influence in Computer-Mediated Communication. Human Communication Research, 30, 234-259.

Lee J et al, 2016. The Relationship between Players' Characteristics and Trolling Behavior: Focused on < League of Leagend >. Journal of Korea game society, 16, 63-72.

Moor P. et al, 2010. Flaming on YouTube. Computers in Human Behavior, 26, 1536-1546.

Olweus D, 1979. Stability of aggressive reaction patterns in males: A review. Psychological Bulletin, 86, 852-875.

Park J \& Song Y, 2010. College Students' Motivations for Playing Online Games and Experiential Satisfaction. Korean Journal of Journalism \& Communication Studies, 54, 131-154.

Patchin J \& Hinduja S, 2010. Cyberbullying and self-esteem. Journal of School Health, 80, 614-621.

Rosenberg M, 1965. Society and the Adolescent Self-Image. New Jersey: Princeton University Press.

Sammut G \& Gaskell G, 2010. Points of View: Social Positioning and Intercultural Relations. Journal for the Theory of Social Behavior, 40, 47-64.

Seo S \& Kim C, 2015. Recognition of the Type and Cause of < League Of Leagend > Trolling. Journal of Korea Game $15,93-110$.

Stafford et al, 2004. Determining Uses and Gratifications for the Internet. Decision Sciences, 35, 259-288.

Suh A, 2012. The Factors Affecting Individuals' Flaming Behavior in Virtual Communities: Theoretical Exploration and Empirical Analysis. The e-Business Studies, 13, 89-114.

Thacker S \& Griffiths MD, 2012. An Exploratory Study of Trolling in Online Video Gaming. International Journal of Cyber Behavior, Psychology and Learning, 2, 17-33.

Thomas A, 2006. Moral Positioning: A formal theory. Grounded Theory Review : An International Journal, 6, 30-31. 
ISBN: 978-989-8533-90-6 (C) 2019

Triberti S et al, 2015. Moral positioning in video games and its relation with dispositional traits: The emergence of a social dimension. Computers in Human Behavior, 50, 1-8.

Yee N, 2006. Motivations for Play in Online Games. Cyber Psychology \& Behavior, 9, 772-775.

Yee N, 2006. The demographics, motivations, and derived experiences of users of massively multi-user online graphical environments. PRESENCE: Teleoperators and Virtual Environments, 15, 309-329.

Zhang Y et al, 2011. Gratifications, collective self-esteem, online emotional openness, and traitlike com- munication apprehension as predictors of Facebook uses. Cyberpsychology, Behavior, and Social Networking, 14, 733-739. 